\title{
The University of Warsaw as a LLL/LWL Integrator: The SWOT Analysis
}

\author{
Małgorzata D. Kisilowska
}

\begin{abstract}
The aim of this paper is to define both strengths and weaknesses of the UW as a higher education institution of universal profile, in developing a package of educational offers designed to answer particular needs of potential students of different kind: secondary school graduates, experienced professionals, people returning to job market (after sickness or maternity leave), immigrants, etc.

Method: the SWOT analysis has been applied to identify all the four types of qualities in two dimensions: an external one, including national legal background or job market situation in Poland, and an internal one, concerning the UW resources and potential in offering modern education.

Findings: Both strengths and weaknesses, opportunities and challenges for the University has been found. The first group includes long experience in teaching students of different age groups, strong connection between research and education, availability of ICT facilities, and learning outcomes of all offered courses, described with qualification framework method. It's weaknesses refer to unstable legal situation, negative attitudes of a part of academic staff towards "competencies \& outcomes" language, insufficient financial resources. Opportunities include flexibility of education system, evolution of social attitudes towards LLL/LWL, integration of education services with market needs, as well as developing positive attitudes among the staff. Competitive schools or trainings, demographical changes, differentiation of the students (their needs and competencies), market response to new forms of qualifications, can be seen as threats, but also as challenges to be faced.
\end{abstract}

Index Terms - Higher education, lifelong learning, life-wide learning, university.

\section{INTRODUCTION}

The higher education system in European countries is under permanent development, facing legal reforms, as well as different needs of the inhabitants, depending (among others) on their age or job situation. Lifelong learning (LLL) and life-wide learning (LWL) are the leading perspectives of evolution of the higher education area. Lifelong Learning is defined as any activity connected with learning, undertaken during a lifetime to develop one's knowledge, improve competencies or qualifications due to individual, social and/or professional reasons [1]. It covers individual or social development in any forms and contexts, either in formal, non-formal or informal ways, such as at home, at work, or within a community [2].LLL aims in an increase of employment ability, adaptation to evolving job requirements, increase of education level in the society, or decrease of

Manuscript received August 19, 2014; revised October 21, 2014.

M. D. Kisilowska is with the University of Warsaw, Warsaw, Poland (e-mail: emka@uw.edu.pl). social exclusion [3]. Life-wide learning refers to developing knowledge and competencies in different areas, changing professions, adapting skills to new expectations, and broadening the scope of one's competencies (both professional and social ones).

Both concepts assume recognition of competencies (recognition of prior learning - RPL) acquired outside a formal education system. THE HE institutions are expected to accept and validate them as equal to adequate learning outcomes of study programmes.

Lifelong learning was accepted as a crucial element of the European higher education area in Prague, in 2001 [4]. It has become an indispensable attitude in modern society, facing permanent knowledge and technological development. We are not able to understand the changes we face if we do not improve our competencies or develop a new one. The requirement of continuing development refers mainly to the adults. However positive attitudes towards education should be shaped as early as possible, starting in childhood.

Changes observed in the European higher education area take place also in Poland. So far the universities for the third age and so-called open universities have been the two most popular forms of education offered for the adults, who have already graduated their degree programs. International directives mentioned above influenced new legal requirements, including formal definitions of LLL/LWL concepts, NQF implementation, and general guidelines for the RPL procedure. Most of these regulations can be found in the Polish Higher Education Law of 2005, with last amendments of July 2014. It defines framework for the NQF implementation, for developing degree programmes answering market needs, as well as for integrating diversified education offer for people of different background, according to the LLL, LWL, and RPL concepts. Previously lifelong learning was recognized only as any courses offered within a formal education system, therefore the amendments mentioned above change significantly legal foundations of adult education in Poland.

\section{II. “The INTEGRATOR” ProJeCt}

The Educational Research Institute (ERI) in Warsaw [5] is the agenda responsible for surveying and describing changes and current situation of Polish education of all levels primary and secondary schools as well as higher education. Its research refers to either pupils' successes, teachers' situation (competencies, requirements, attitudes, etc., or system's readiness to answer social needs and expectations, shaped by local, national, and international background. It is a partner in international surveys of learning outcomes, like 
PISA, and other (like SHARE).

In 2014 the ERI runs the subproject $A$ higher education school as $L L L / L W L$ integrator (hereafter called "the Integrator"), as a part of the general project Development of content and institutional guidelines for the National Qualifications Framework and the National Qualifications Register implementation for lifelong learning.

An integrated qualification system, based on the NQF, will enable and facilitate a lifelong learning of individual users. HE institutions shall more intensively integrate their LLL and LWL strategies.

The subproject aims at the model proposal of reorganization and integration of a higher education offer, based on the National Qualifications Framework and defined learning outcomes of particular levels. This aim comes from the observed absence of integration of education with $\mathrm{NQF}$ and recognition of prior learning, in particular the learning outcomes gained apart from formal education. The following tasks are to be realized as a part of the Integrator:

1) Diagnosis of the UW readiness to fulfill the LLL/LWL integrator role, based on legal requirements, educational offer, available teaching methods and tools, including in particular:

- Internal integration of the UW interests and needs.

- Integration of its educational offer and the job market needs (including those of weaker social groups).

2) Development of recommendations and guidelines of activities aimed in the UW organizational change regarding the LLL/LWL perspective, in particular the RPL procedure, including:

- Methods of recognizing the LLL/LWL integration areas in HE institutions.

- Developing an educational offer in regard of an university organizational structure and resources (staff, infrastructure), identified needs of target groups, job market needs, and modern teaching methods and tools (including e-learning).

- A procedure of NQF implementation as a basis for developing educational offer.

- An education counseling and enrolment of the candidates.

- Cooperation with the institutions concerned with social groups of specific needs.

- Establishment of a UW RPL centre.

- Permanent modernization of an ICT infrastructure.

- Education promotion.

Planned activities become a part of monitoring the NQF implementation into the Polish education system. Higher education is the most advanced in qualifications framework implementation, so it is the best available field to study the methods used, to diagnose if they are used adequately regarding a lifelong learning strategy, and to show the perspectives of their creative application.

This is a two-level concept. The first stage is being realized by $5 \mathrm{HE}$ partners representing different types and fields of education: the University of Warsaw (an university), the Warsaw University of Technology (an university of technology), the Warsaw School of Economics (an economic university or equal), the State School of Higher Professional
Education in Elblag (a higher vocational school), and the West-Pomorian Business School in Szczecin (a private higher education school). Their goals are to analyze the potential of particular types of HE institutions as LLL/LWL integrators. Their experiences, evaluations, and development trends will be then merged (as far as possible) on the second stage into one universal model of a HE unit as a LLL/LWL integrator.

Finally, HE institutions of different types in Poland will receive detailed guidelines for effective NQF application for lifelong learning support within binding law. Effects of their activities should be disseminated among the whole academic community, including students and candidates, lecturers and administration staff, as well as local communities and employers.

\section{THE UNIVERSITY OF WARSAW}

The University of Warsaw is an academic institution of universal range in both research and education. It comprises of 20 faculties offering more than 400 academic degree programmes (ranging from Philosophy to Informatics, and from Nanostructure Engineering to Cognitive studies), with more than 53000 of MA and BA students, and 7000 of research, teaching, and administration staff. It offers BA, MA and $\mathrm{Ph} . \mathrm{D}$. studies on both regular and extramural basis, for young adults and students from other age groups. There is also a wide range of post-diploma studies for people requiring formal recognition of the competencies they already have, or for those who need to get new knowledge and qualifications they have not had so far. Its mission refers to research and education services, as well as to social responsibility and public service.

The University develops also atypical education services, offered by a few agendas. One of them is the Centre for Open and Multimedia Education (COME) [6], aiming at expanding and facilitating access to higher education for different users, bridging social, geographical, or time barriers. This is possible thanks to new information and communication technologies. Practically, the COME offers Internet courses (e-learning and distance learning) for the students regardless their place of residence or previous education. It also cooperates with the UW Open University (UWOU) in development and realization of online courses.

The UW Open University was established in 2008, as an innovative UW concept in Poland. It offers (paid) education for the adults (16+), regardless of their education, social situation or beliefs, with no enrolment requirements. It answers and/or awakes lifelong learning needs. The UWOU strongly advocates also the concepts of LLL and LWL, initiates and supports research concerning adult education in different forms. As a university unit, it cooperates with faculties in developing educational offer. In the year 2014 more than 42000 of students take part in UWOU courses, most of them (41\%) from an age group of 31-40 [7].

\section{THE SWOT ANALYSIS: STRENGTHS}

A couple of strengths have been recognized so far, 
regarding the UW potential in LLL/LWL integration. These are: education strongly related to research; the legal regulations as fundamental for any activity of that kind; learning outcomes defined for all degree programmes (on both general and a particular level of each course offered); experiences in e-learning; experiences in teaching students of different backgrounds; experiences with recognition of prior learning or qualifications obtained in non-formal and informal ways; contacts with the employers.

The UW is the leading Polish university in both research and education. With almost 200 years of academic experiences (founded in 1816, it will celebrate the Jubilee Year in 2016), it has been a leader in many research fields. Employing acknowledged scientists, it offers the students a unique possibility of learning from those who are in fact "at the front line" of discovering world rules and peculiarities, and building new knowledge. They have a chance to take part in research processes, and observe effective methods of research work.

Legal foundations for the UW activity include international and national regulations [8]-[11]. The Polish academic community, represented by the Polish Rectors' Foundation, the Conference of Rectors of Academic Schools in Poland, and the Conference of Rectors of Vocational Schools in Poland, developed in 2010 the Strategy of the higher education development for the years 2010-2020, where the lifelong learning concept was defined.

The UW mission and strategy declarations, accepted in 2008, refers to the idea of lifelong learning, mentioned in the European universities' charter on lifelong learning of 2008 [12], accepted by the European University Association. The Charter obligates them to enable realization of the LLL, LWL, and RPL ideas, i.e. to accept the rule of equal learning in different forms, places, and lifetime, and to validate effects of prior learning. The UW recognizes its integrating role in regard to the needs of:

- People interested in qualifications and competencies improvement.

- Changes at the job market.

- The local community.

- People with significant geographical, time or social barriers in university education.

- Secondary school graduates (integration of education levels).

- Also the needs of individuals and the university staff.

In June 2014 the UW Senate accepted the midterm strategy of development for the years 2014-2018. It refers to the LLL concept, comprising of such topics as inter-faculty cooperation, enlargement and flexibility of educational offer, developing modern LLL services (including trainings and individual courses), and developing the organizational basis for validation of learning outcomes reached apart from a formal education system.

Either university, or faculty regulations declare cooperation with the employers in the process of development, modernization, and/or adaptation of degree programmes. The role of LLL has consecutively been perceived by faculties and departments, as it is expressed in their particular strategies or regulations, with expressis verbis mentioned LLL, post-diploma studies, or forms of education other than traditional degree programmes.

Qualifications framework was introduced into the Polish higher education system in 2011. It means that each HE institution was obliged to describe curricula in general, as well as each course, with learning outcomes to be reached by the students. The Polish National Qualifications Framework is prepared separately for different groups of disciplines, like: humanities, social sciences, sciences, natural sciences, health sciences, economics, technical sciences, veterinary, forestry, and farming, and the arts [13], [14]. In the academic year 2011/2012 the University of Warsaw units have had to decide in which field each degree programme they offer belongs, and to define their learning outcomes. Detailed outcomes for each course can be defined each year by the lecturers individually. However they must strongly refer to the outcomes of the programme level.

This process was managed at a university level; quality and approachability of curricula outcomes was mutually peer-reviewed within three teams: for humanities, social, and applied sciences, by representatives of all the faculties. We assumed this process was helpful in regard of precise formulation and actual reachability of expected learning outcomes. Finally, we have had these outcomes listed for all BA and MA, as well as part of post-diploma programmes offered at the University of Warsaw. This is a strong fundament for designing programmes focused on outcomes, not content, for developing descriptions of qualifications available for the candidates with different education or professional backgrounds.

Qualifications framework actually implemented to an education system, with defined learning outcomes, is a platform for recognition of prior learning. The UW faculties and departments have the tools for comparing and validating candidates' levels of knowledge, skills and social competencies with those they defined for their programmes. The aforementioned Polish Law on Higher Education defines the requirements and limits for the RPL practice, for example final secondary school exam passed, number of years of professional work (different for BA and MA studies), maximal portion of $50 \%$ ECTS for a curriculum to be validated basing of candidate's qualifications obtained previously. There are also international experiences [15] and projects [16] we can refer to, discussing and preparing internal UW solutions for the RPL procedure.

At least a few of the UW faculties have some experiences of the RPL activity, although in a quite small range. These are:

- Validation of professional experience as equal to internships.

- Recognition of language certificates of adequate levels.

- Recognition of learning outcomes achieved during realization of the same level (BA or MA) programmes at other higher education institutions.

- Recognition of formalized sport activity as at least equal to obligatory physical classes at the BA studies.

The University of Warsaw is strongly engaged in developing a learning outcomes-based academic culture. It runs workshops on NQF, designing curricula, calculating ECTS in regards of students' works and effects. The 
academic year is divided into 2 semesters, 5 weeks modules each, plus two summer modules - such an organization enables flexible adaptation of teaching modules, which can be realized more intensively or in a standard way.

The Centre for Open and Multimedia Education is a modern unit responsible for developing an e-learning offer. Currently (2014) the following types of courses are offered (as either e-learning or blended learning): language courses, faculty courses (modules of degree programmes), post-diploma courses, repertories, general trainings (copyright, information literacy, safety, etc.), trainings for the UW staff, projects, repositories (catalogues of files for the students, with no other learning activity), and open courses for people not being the UW students. In 2013 there were 32 thousand active users of the COME Moodle platform, offering 96 UW courses, 205 courses of 5 languages, languages tests, 15 courses for the users other than UW students (participated by more than 130 people) [17].

E-learning flexibility makes it a good tool for any type of education - formal, non-formal or informal. It reaches different groups of users, enables social integration, individual development, intercultural dialogue, as well as development of information and media literacy [18]. E-learning is a service particularly useful for those who cannot participate in stationary classes due to different barriers: time, place, or social ones (the disabled, mothers caring for babies and toddlers, etc.).

The University of Warsaw has quite a long tradition of teaching not only "regular students" - young adults, secondary school graduates - but also people from other age groups. The latter can enroll to extramural degree programmes, the COME courses mentioned above, or to post-diploma studies.

The latter are often prepared in response to the job market needs, as ordered by the employers or as a result of cooperation with other external stakeholders (like local communities). There are also Polish language courses for the foreigners, which can be an integral part of cultural and language integration of the immigrants.

The UWOU is a part of COME. Its strategy defines adult students as people aware of their needs and goals, independent in decision-making, and responsible for individual development. Courses offered by the UW Open University are realized in different forms (lectures, discussions, seminars, but also visits to specific places), in Polish or English language. The learning outcomes of the UWOU courses are neither described in the same way as those of regular degree programmes, nor calculated with ECTS. However, final certificates describe the kind of outcomes, and therefore they can be revised as a confirmation of knowledge and/or competencies of their owners in further RPL procedures, if necessary.

The list of courses offered for the first trimester of the academic year 2014/2015 can be found in the Appendix. As one can see, they are grouped in 6 categories: the culture $\&$ art, the human \& society, the business, economy \& law, the science \& technology, the human \& environment, and the languages \& nations. The latter is the largest, including more than a hundred or so language courses of different levels, as well as courses on particular national or regional cultures. It seems to be obvious that there are many clients interested in developing their language skills, and UW teachers are well prepared with working with non-students groups in this range.

Cultural and sociological categories include approximately 50 options each, either of theoretical character, developing knowledge of a specified field, or focused on soft competencies (the most popular topics are interpersonal communication and public presentations). The smallest is that concerning human and environment, with only 3 options. Advanced ICT courses prevail within the science and technology category.

As it was mentioned, the UWOU education service is available for people aged 16+. It comprises also the seniors, who could have applied previously to the special "University of Tertiary Age". At present the UWOU participants are joined in mixed-age groups, which seem to foster social, intergenerational integration and mutual inspiration.

The UWOU is also an organizer of other activities: debates, lectures, or exhibitions, which can be seen as a form of invitation and integration with the local community.

The University of Warsaw is also well recognized among the youngest Poles. It has been cooperating with the initiative called the Children's University [19] for many years, offering lectures, classes, and laboratories for its students (aged 6-14), answering their most pertinent questions, inviting them to the laboratories, libraries, and auditoriums, as well as sustaining and developing their curiosity and passions with modern didactic methods.

All language courses at the University of Warsaw - either for the students or other users - have defined learning outcomes and are relegated to adequate levels (from A1 to C2) of the Common European Framework of Reference for Languages (CEFRL) [20]. Certification exams are also described with learning outcomes referred to this Framework. Language requirements are described within the Polish NQF for higher education with the same categories. That means, that whenever or wherever a student/user obtain language competencies, confirmed with adequate diploma or certificate, they can be verified positively and recognized as equal to an adequate module of a degree programme. He/she obtains also the ECTS points. Language competencies referred to the above mentioned Framework, and confirmed by the UW or any other certificate is recognized in the Ph.D. procedures. All means that the UW language teaching is integrated completely.

Teaching staff and Ph.D. students are encouraged to develop their competencies within "The Modern University" a comprehensive support programme [21], co-funded by the European Union - Human Capital Programme, and realized in the years 2009-2014. It aims for the empowerment of the didactic potential of the entire University, as well as a scientific development of its participants. The project comprises four modules: grants for the best Ph.D. students and young researchers, foreign internships for the latter, grants for visiting professors in the UW, and training programme for the teaching staff. Current challenges of the academic education are discussed during methodological workshops of conferences introducing - among others LLL/LWL and RPL concepts to the researchers and students. 
The project is a perfect occasion to prepare for changes being implemented in HE area.

\section{THE SWOT ANALYSIS: WEAKNESSES}

A SWOT analysis requires further reflection on weaknesses or problems concerning discussed topic. The University of Warsaw cannot enjoy its strengths and rest on its laurels. The next step is to name the weaknesses, which are: traditional structure of the faculties, unclear legal regulations, information and communication problems, quality of learning outcomes' frameworks defined for each programme or course, teaching methods, staff attitudes towards changes, and - last but not least - also students attitudes towards responsibility for their education careers.

Traditional structure of the University, with strong faculties' autonomy, is usually perceived as an advantage. However, it sometimes results in similar or even alike initiatives, reasons for which can be found in poor knowledge of each other's education offer. It results in useless dispersion of university resources instead of their concentration on the best ideas. Cooperation and communication seem to be indispensable in development of a coherent education offer.

This difficult situation is strongly connected with poor information flow. Lack of credible and valid databases has been notified, in particular the one of trainings and courses offered by the UW units (with defined learning outcomes), or the other - of current, complete, and integrated data about all the UW degree programmes and courses. The UW ECTS Manual is often incomplete - as the faculties do not upgrade it with current data in case of programmes modernization of changed ECTS calculation.

A qualifications framework was introduced into the Polish higher education system in 2011. However, it has been applied in a run (due to ministerial requirements), and perceived mostly as a specific, bureaucratic method of describing degree and post-diploma programmes in a new, "learning outcomes" way. A proportionally small group of staff was adequately informed and trained to use NQF for the benefit of teaching and the students, as a new tool, in the context of a LLL/LWL strategy, particularly useful in developing flexible offers for different users and within a RPL procedure.

Therefore, learning outcomes are defined poorly for at least a part of programmes. They are too general or not balanced among all the courses or modules a programme consists of. They still are more content- than competence-oriented, according to previous guidelines and teaching staff's habits. After three years of the NQF implementation, and new experiences gathered, learning outcomes require reorientation and redefinition: either these for standard degree programmes, or those assigned to LLL/LWL courses offered by university units to the students or any other users.

The lecturers' resistance towards NQF is an important problem here. They quite often perceive this change from content to learning outcomes perspective only as an additional task, with too much documentation. It is difficult to believe that this new orientation would be harm neither for them (and a teaching process) nor for the students and their competencies. This resistance comes sometimes also from their laziness or passivity.

The ECTS calculation also needs permanent attention and upgrading, along with modernization of content and outcomes of particular courses, to reflect actual student's or user's work and efforts, regardless the type of education service he/she benefit from. This need refers in particular to COME courses and post-diploma studies, as not all of them have learning outcomes defined already. The latter are poorly related to the NQF, as there are no national or internal regulations concerning offer dedicated separately for BA or MA graduates. Therefore, it becomes quite difficult to balance (or to differentiate) learning outcomes for lower or upper level. The other thing is, that the UW faculties have prepared a small number of post-diploma studies designed intentionally for one or the other group of graduates so far.

Recognition of prior learning has not been very popular at the University so far. As it was mentioned above, there were just a few types of courses or modules to be credited on the base of external certificates or professional experience. However, those decisions were made individually in both personal and course aspects. There are neither detailed regulations nor declared resources indispensable for starting RPL as a formal procedure. It also seems to be difficult to verify particular competencies in regard of degree programmes of more academic, theoretical than practical character, which make the major part of the University of Warsaw BA or MA offer.

Each type of an education offer at the University of Warsaw requires permanent revision and verification in the light of data coming from the graduates' careers monitoring. This task has become obligatory according to the Polish Law on Higher Education, however we have not gathered much data so far, and we are still learning how to analyze it and what we shall focus on.

Teaching at the UW is dominated by traditional face-to-face methods: lectures, group works or discussions, laboratories. E-learning, education games, case studies or projects are still not very popular. Methodological trainings are indispensable to change the situation, concerning also computer and media competencies, increasing trust and building positive attitudes towards new forms of education. Increased interest in e-learning requires modern ICT infrastructure, as well as adequate legal foundations.

The students' learning competencies are also poor sometimes. They are used to answering tests of different kinds, very popular in both primary and secondary schools. A secondary school final exam requires strict answers, with selected exact words or phrases pupils learn by heart. In other words - they are not very familiar with discussions, hypothesizing, searching for answers, being an active partner in a teaching-learning process. It takes plenty of time sometimes to activate them and to inspire them to individual or group research.

Education services for "atypical" users (seniors, children, teenagers, working people) are too often perceived as secondary in the light of the UW statutory goals. Most of the academic community has not become acquainted with the changes within a higher education; a part of it still tries to defend traditional methods and contents as the best, proven 
solutions. It is hard to imagine for them the innovative roles of the University within a new social, educational, and professional contexts.

\section{THE SWOT ANALYSIS: OPPORTUNITIES}

What opportunities can be found in the idea of integrating LLL/LWL services in the University of Warsaw? They can be discussed in different dimensions: institutional, local and regional, or at last national and international.

Direct institutional benefit coming from LLL/LWL and RPL development is an increase of number of the students. In time of population decline, higher education institutions of all types must consider the number of candidates to standard degree programmes. The University of Warsaw does not have any problems of this kind yet, which does not mean that they will not be faced in a near future. Differentiation of an educational offer, in particular the services prepared specially for groups other than young adults, can solve at least partially potential problems with obligatory teaching hours to be realized by the staff. With students' groups decreasing, the faculties prepare more optional courses for either the students of their programmes, those studying at other faculties, or any other users.

The more courses offered-the better use of the researchers' knowledge and experiences. The smaller groups of people actually interested in a topic, the more engaging and activating didactic methods can be applied, like projects, games, or discussions, with individual contact between a teacher and a student. The courses can be tailored according to the students' level of knowledge, more specific, and though more engaging and challenging.

Actual number of students and users results in the amount of public funding, i.e. a ministerial subvention for the UW, granted annually to any public higher education institution in Poland. Its amount depends directly on the number of students enrolled. The other users have had to pay for their attendance to open courses so far. If the courses are free of charge, these categories of participants should be treated in the same way as the students, and calculated altogether as a basis number for a subvention calculation. This would require amendments in a binding law, of course.

All three - LLL, LWL, and RPL - perspectives change higher education diametrically. New forms and new recipients require revision of curricula and courses, for example new organization of knowledge, competencies, and learning outcomes, regarding both degree levels of the students, or their general knowledge and preferences (ex. technical or historical thinking). Entrance requirements for different courses shall also be defined precisely, but not rigidly, to leave them open for different types of potential participants.

NQF enables development of individual, profiled studies for those who want to reach unique qualifications offered by different faculties, at several degree programmes or within other education services. Such a system would be much closer to individual professional career development than to education of a group of people of unified knowledge.

Courses' contents and teaching methods can be verified regarding the recipients' competencies. The latter differentiation, for example groups joining "standard" students with people already working or even retired, can be beneficial for each of them, as an occasion for experiences, knowledge, and opinions exchange. Didactic work with such a group is a methodological challenge. But the teachers can also learn from the participants, who can ask important questions, put attention to inconsequence, find practical solutions, present life examples, etc. The group members can also learn from each other-exchange knowledge or experiences.

Development of open courses, accompanied by implementation of the RPL procedure, can also be analyzed regarding the needs of teenagers-still learning in secondary schools or their graduates. Would it be possible to prepare so-called introduction courses, presenting advantages, difficulties or oddities of different disciplines, to help them recognize their talents and interests and in consequence to choose consciously and wisely a degree programme? Enrolled to such a programme, they would be allowed to apply for recognition of their competencies obtained previously.

This idea would support the UWOU plan to establish the Education Advisory Service for the youth and the adults. It is planned as offering advocacy and help in defining an individual's education paths and in reaching their goals. Information about education services of either UW or other higher education institutions in Warsaw and its region will be available there.

The LLL/LWL integration at the UW can answer the need of short HE programmes (on the $5^{\text {th }}$ level of NQF - between secondary school and BA studies), which is expressed directly in the strategic document Poland 2030 development challenges [22], [23]. Short programmes are expected by the employers and other stakeholders; their usability is confirmed by other countries' experiences. They can also be discovered as useful for people with qualifications below BA enrolment requirements or for the immigrants from the countries with the $5^{\text {th }}$ level of NQF included in a formal education system. Depending on employment situation and market needs, they can also become an alternative for BA studies. Learning outcomes from this level could probably be accepted as a part of BA programme in the RPL procedure.

Teaching people active professionally makes an opportunity to know better market needs of specific competencies. Media discussion which took place in Poland in 2012/2013 showed directly that university graduates have perfect theoretical knowledge, but they can hardly translate it into real life problems, and they lack seriously soft competencies, like team working, interpersonal communication, networking, etc.

Cooperation with the employers' representatives during curricula revision or development, which is a condition named in a faculty's quality education system all over the University of Warsaw, is an another opportunity to assess needs regarding all types of competencies and skills required at the modern job market.

Contacts with the employers as well as with the UW graduates are the best source of information of their real placements, careers' development. It lets us know where they 
are working actually and why. Sometimes data revealed from a graduate's survey revelations are quite surprising. For example the graduates of a degree programmes in history quite often are employed in bank credit departments, because of their strong competencies in reading documents and finding indirect information. Graduates of ethnography and anthropology are highly valued in marketing and promotion.

Accreditation of degree programmes given by professional organizations has not been very popular in Poland so far. However, one can find a few examples of such procedures. For example the Polish Librarians' Association runs an accreditation commission, evaluating workshops, trainings, or any other non-degree, LLL/LWL initiatives. It has not evaluated a degree programme in library and information science so far.

There is also an opportunity for developing a strong higher education research team within the University of Warsaw the Open University, focused on adult education, the LLL/LWL theory and practice in Poland or abroad. This is a unique occasion for observation of implementation of such an education concept, enabling up-to-date analysis, reactions, and research. The UW LLL/LWL services have been monitored from the very beginning [24]. The following variables are being monitored: the users' demographic data, level of their engagement in education or other UWOU activities, also the ways they spend their free time or benefit from other organized forms [25]. Having a strong research background, the UW has also a potential of teaching specialist in adult education - offering courses for teachers or actually specialists in any field, with educatory obligations (healthcare professionals, IT specialists, etc.).

Taking these opportunities, the University of Warsaw has a potential of further development and keeping a leader position among the Polish higher education institutions, as an education "trendsetter". With its tradition, experiences, innovative attitude, qualified teaching, administration and management staff, the UW has both reasons and a strong background for exploring new education services.

The other category of opportunities includes theses of local and regional dimensions. The LLL/LWL strategy implementation means, that people, in particular living in Warsaw and the Masovian region, have a wide range of education services to choose the best matching their needs. With well-developed RPL procedures, and many positive experiences with validation of competencies obtained within informal or non-formal education, people will become more willing and eager either to apply for recognition of the competencies they already have, or to enter different forms of education (no matter UW or the other). They will become convinced that they can develop their competencies and verify them, whichever the system, pace, or field they choose.

One can also expect that the RPL implementation, focused on evaluation of competencies and learning outcomes, can influence the quality of non-formal education services of any type. Their organizers will have to think in a longer perspective, and consider the relation between potential UW recognition and number of their clients, well-informed about actual effectiveness of their offer. In other words - the UW as the LLL/LWL integrator has a potential of increasing quality of education in general.

The courses, workshops, science picnics, etc. for children and teenagers are effective tools for awakening their creativity, interests, talents, and the need for lifelong learning, but also for establishing relations. The latter can play a decisive role in making future choices regarding place and field of study. There is a positive example of the UW Faculty of Chemistry. Direct contacts with secondary school pupils, organization of contests in chemistry, courses for the Polish Children's Fund [26] (funding scholarships for talented pre-university students), annual participation in the Science Festival results in effective promotion, awakening interests and influencing future choices of teenagers [27]. Similar activities are being realized by teaching staff or Ph.D. students at the Faculty of Philosophy and Sociology [28], or the Faculty of History [29] - among the others. The latter organizes or co-organizes concerts and exhibitions, participates in different forms of knowledge promotion.

Universities can intensify their cooperation with local stakeholders other than employers only, for example employment services, job centers, public libraries, or non-governmental organizations working with different social groups.

Last but not least, formal recognition of competencies regardless of the way they were obtained gives a better chance for finding a job and protect against social exclusion those who are in difficult life situations, for example immigrants.

International and national regulations and guidelines built foundations for a modern and flexible education system. That is also an incentive for evolution of social attitudes towards LLL/LWL - either the public entities developing such services, or potential clients, who may have not had an idea of obtaining new competencies so far.

Cooperation with different stakeholders, monitoring the graduates' careers, contacts with both the employers and the employees, as well as surveys of job market, enable recognition of the most needed hard and/or soft competencies. Such a monitoring is indispensable for integration of an educational supply and a market demand. As the LLL/LWL as an inherent part of a higher education area is quite a new phenomenon, we may expect development of this segment of education services, along with discovering competencies needed actually at the market. The aforementioned graduates can become both "permanent clients" of the UW education services, choosing them as known and reliable, or people who can name their demand and submit them to an institution (university as a whole or particular faculties) they appreciate.

A group which is very active as LLL clients are school teachers. Their decisions depend partially on regulations imposing permanent education as an obligatory element of a professional career. Post-graduate studies for BA or MA graduates, integrated with degree programmes respectively, can make an attractive offer for these students.

Post-graduate studies can be also discussed as an attractive solution for BA graduates active on a job market, who want to verify and certify their competencies applying for the RPL procedure. Such solutions can be perceived as a coherent way of ascending an "education ladder".

There is also an opportunity of developing positive 
attitudes among the teaching staff, towards the HE reforms. A "competencies \& learning outcomes" approach is actually more flexible and open than previous, content-based curricula. Diversification of an educational offer is a perfect occasion to prepare very specific courses, strictly referred to one's research interests. Effective teaching, aiming at well-defined competencies, can be realized with many activating methods, chosen according to a specific topic and to teacher's predispositions.

Integration of a LLL/LWL approach within the higher education area, after a couple of years of experience and careful monitoring, may lead to development of general guidelines for the following institutions modernizing their services.

An optimal education system, engaging stakeholders and clients of different background, as a platform of knowledge, competencies, and experiences exchange, can influence positively a social capital in Poland. Our society - as many others - needs competent people, as well as mutual trust and belief, that whatever one really can do, it can be positively verified and promoted.

LLL/LWL integration in general perspective empowers positive competitiveness of individuals and entities (including $\mathrm{HE}$ institutions), employability, and social integration. As the Commission for European Communities stated: "Public and private benefits [from LLL - M.K.] include greater employability, increased productivity and better-quality employment, reduced expenditure in areas such us unemployment benefits, welfare payments and early-retirement pensions, but also increased social returns in terms of improved civic participation, better health, lower incidence of criminality, and greater individual well-being and fulfillment." [30]

\section{THE SWOT ANALYSIS: THREATS}

Each new undertaking entails not only opportunities, but also threats, which have to be carefully analyzed. The question arises whether there are more benefits than losses in a final result of our decisions.

This new approach to LLL/LWL as an integral part of higher education leads to significant changes in the social role of the universities and their explicit responsibility for teaching highly qualified professionals equipped not only with practical skills, but with broad theoretical knowledge of a particular discipline. The lecturers often cannot accept the necessity of modernizing previous academic, theoretical curricula, to make the more practical and simply useful nowadays. They worry about the future of degree programmes in classical, theoretical disciplines, like philosophy or physics, biology or mathematics, history or chemistry. Diversification of programmes, courses, students and non-students among the recipients of the university offer is perceived as a phenomenon weakening its autonomy, as a transformation from an academy to an education service functioning according to market rules.

The relations among the curricula (their outcomes) and the disciplines shall be described in a new way, which can be perceived as both threatening and challenging.

The UW staff is strongly afraid of a decrease in teaching quality due to enrolment of a large amount of candidates with an inadequate educational background. This anxiety refers not only to the UW itself, but also to other academic institutions. A student group comprising of people of different professional, educational, and practical backgrounds, can be very inspiring and creative, but can also be difficult in a didactical perspective. Selection of contents and methods adequate for experienced professionals or secondary school graduates at the same time requires more effort and deliberation from the lecturers.

Another mentioned threat is of a financial character. Who would pay for university education services offered to non-students (if students are defined as those fulfilling enrolment requirements, including the final secondary school exam passing, as stated in the national law and institutional regulations)? Would it be covered, at least partially, by a ministerial subvention? Or should the open courses be paid by their participants individually? Would it be a general rule for all types of open courses, or should one categorize them and offer a few of them free of charge, for example those dedicated to children?

This problem can be analyzed also in a wider, social perspective. If open courses are paid, then how of their many potential participants can afford that kind of competencies' improvement? A kind of contradiction arises between the under-educated people or those facing life changes, in real need of new or upgraded competencies, but no resources for that type of activity, and those who can afford education of different kinds, but do not need it that necessarily. Will the LLL/LWL offer actually reach these who are in real need of learning? For whom will it be affordable?

Threats related to the RPL procedure begin with the same financial question, i.e. who pays, for which activities exactly, and/or how to calculate a due amount? The Law on Higher Education lists only a few regulations concerning validation of learning outcomes or competencies, therefore an analogous list of doubts arises. There are no transparent rules of financing validation procedures, including staff training, establishing special RPL units on either university, faculty or department levels, or performing these new tasks.

We believe details are left for institutional decisions. However this situation is burdened with a risk, also a risk of abuse. The latter refers mostly to a potentiality of too generous, too "user-friendly" validation offered by $\mathrm{HE}$ institutions of poor-quality, either public or private entities aiming in growing rich rather then education itself. There are also very detailed problems, ex. g. the one concerning enrolment requirements. These are listed in details for each and every degree programmes offered at the University of Warsaw. A few faculties or departments require a special entrance test, due to their specifics (like advanced knowledge of music notation at the musicology programmes). Enrolment to the others depends on the results of the secondary school final exams: courses chosen and passed by the candidates, and a percentage rating they gained. The question refers to the requirements for the RPL candidates. According to the Law, they must have at least positive result of this exam, but should it be expected on the same level as from the candidates enrolling in a regular mode to degree programmes? Why - or why not? 
A few faculties do not recognize qualifications obtained out of formal education as valuable or at least equivalent to the ones to be acquired during academic studies. They mention difficulties in verification, potential abuses or decrease of education level. The RPL idea is perceived rather as a threat for the University tradition and social position, and in consequence as a risk of significant decrease of the social need of academic education. Staff attitudes seem to result from their poor understanding of the "learning outcomes" concept, lacking experiences (in particular good practices), and depend on the faculty, i.e. discipline: of more practical or academic orientation. The most challenging seems to be negative, mistrustful attitudes towards learning outcomes gained apart from formal education system, as equal to those worked out during regular, academic studies.

The Act allows at most $20 \%$ of students admitted to a degree programme on the RPL procedure. However there are people worrying for a decreasing number of "regular" students. These candidates who have not had any other option so far, even having an impressive professional experience, entered their degree programmes (usually in an extramural mode) and only a few modules (like internship, as mentioned above) could have been recognized referring to their practical knowledge. The RPL option enables them to crediting learning outcomes for up to $50 \%$ of ECTS. This situation has its financial and organizational consequences. The latter refers to the number of students' groups, and directly to the number of teaching hours to be run by the staff. The fewer students, the fewer teaching hours, which is obligatory in a given amount for each and every lecturer. There is a general question - if open courses for non-students can be included in the amount of obligatory teaching hours.

Another problem refers to relations between post-graduate and MA studies. As suggested above, MA graduates active on a job market could improve or diversify their competencies enrolling to post-BA studies, not - as it happens now - to MA studies. Then: what are actual differences between them? Can them be diversified within the NQF? Can they be expressed in learning outcomes? Do the post-graduate studies threaten MA programmes or not? How to estimate if this problem is a real or theoretical one?

A LLL/LWL market in Poland, including post-secondary schools, higher education, trainings, courses, workshops, etc. is hardly recognized. There are too many entities of temporary character, being established in response to the market situation induced by legal requirements (for example concerning certification of paedagogical competencies of people working with children and youth, organizing holiday camps, etc.), offering paid trainings of poor quality to people in need. Companies which are smaller than universities have an advantage of being more flexible and faster in reactions to market changes. The universities act on strict legal foundations and many innovative solutions require previous changes in formal regulations, which takes time. Therefore training industry can be an important opponent in searching for potential customers of education services.

Last but not least - we do not know the scale of potential interest of the public in a LLL/LWL/RPL offer in local or national scope. How many people actually want to improve or develop their skills? Can they afford that? Are the employers interested in their employees' professional development regardless of the type of course they attend?

The threats discussed above can also be perceived as challenges for the academic community. An attitude towards them actually influences our choice and activities - whether we will try to avoid them or to face them and change problems into successes.

\section{FINDINGS}

The LLL/LWL is not a brand new perspective for higher education, although in its current interpretation it changes diametrically the social role of higher education institutions. The University of Warsaw as an integrator of lifelong learning has a strong research and teaching basis, log experience, and position supporting realization of this task. Its education offer is well rooted in its research activity, warranting transmission of a brand new knowledge, contacts with the experts in particular fields, and development of highly-recognized competencies.

However, integration of these services, in particular the RPL procedure, as the most challenging element, requires specific factors for a success. The first are positive attitudes of the staff - to be confirmed or worked out, if necessary. These include either teaching staff attitudes towards NQF and resulting changes, or management and administration staff, to make organizational structures and decisions both stable and flexible, enabling quick reactions for changing market needs. The other - careful research of market need as a basis for development of an adequate education services. The offer should be described precisely with learning outcomes and competencies, in a understandable and encouraging way. Actually, courses' consistency with NQFs, their potential verification as partial competencies of a degree programmes, clear formulation of learning outcomes and competencies of the graduates seem to be of utmost importance, and should be regularly updated according to both current research knowledge and market needs. The high-quality education services must be offered constantly.

The role of LLL/LWL integrator emphasizes the University of Warsaw (or any other higher education institution in broader perspective) social obligation of (direct or indirect) monitoring and verification of education and training business. Further implementation of all new regulations concerning NQF, LLL, and RPL will demonstrate whether the legislation is clear enough in its statements, and achievable in everyday life, or a few amendments will become indispensable.

The SWOT analysis described above can be an example of the scope and range of a study to be realized when a university or any other HE institution faces structural changes of the higher education area. There are several important aspects which should be considered.

Legal basis is the first one. It comprises of international, national, and internal regulations influencing a lifelong learning courses organization, their availability, and its possible limitations. The other one is a university's educational potential in research, people, and infrastructure perspectives. Research specializations, highly-recognized achievements, stable academic positions are decisive for 
development of attractive and valuable courses and programmes. Experts in their fields, with advanced teaching skills (verified regularly in students' questionnaires and auditing) and convinced that knowledge usability does not have to harm an academic tradition, are also a key element of the success. No less important is the infrastructure - either convenient or sufficient auditoriums, classes, libraries, laboratories, etc., or the ICT infrastructure, which is crucial for developing online education services for the users unable to take part in classes personally.

The market aspect cannot be ignored here. The employers' representatives must be included in counseling and revision processes concerning educational offer for the students or non-students, regarding professional competencies needed and/or expected in the nearest future to be indispensable, to make the courses not only tailor-made, but also always a step ahead of the needs. That includes the content, media and soft competencies, the latter to be developed thanks to activating methods of teaching and learning. Methods and tools of market research and/or cooperation can be developed individually by universities or their faculties.

Another concern is the social interest and potential, i.e. the average number of the group who may become a client of LLL/LWL services due to their job situation, age, or other circumstances. The economic situation is still a very important factor at this time in Poland. That must be considered in our current discussion on the RPL implementation.

Other education institutions are also important in the analysis. A group of them should be perceived as offering competitive services, which can actually animate and influence positively the general education offer. The others-like secondary or post-secondary schools, or training companies-may become partners in a well-developed lifelong learning supply chain.

Finally, positive and negative potential effects of the changes being introduced need to be discussed deliberately, to withdraw unnecessary mistakes, and the whole process of LLL/LWL integration should be carefully monitored for early detection and early prevention of possible malfunctioning.

All these aspects of the LLL/LWL integration in a HE institution should be analyzed in local, regional, national, and international scopes, as there are different entities, needs, and circumstances on each and every level to be considered.

\section{CONCLUSION}

The Integrator project team strongly believes that changes which have been introduced in the Polish education system, in particular the higher education area, are both unavoidable and necessary in a modern knowledge society which has been developing in many countries.

The University of Warsaw (as any other Polish university) is obliged to develop social awareness and needs concerning lifelong learning as a common lifestyle. Developing education offer for the adults is a mission goal nowadays. Developing new competencies and new knowledge among its users, the universities counteract social exclusion and support weaker social groups in their struggle for a better future.

The university as an integrator fulfills the mission proposed by Jacques Delors at the beginnings of the seventies, becoming a common, meeting place for the adults who want and need to learn permanently. "Universities would contribute to this process by diversifying what they offer: (...) as some of the main meeting-places for learning throughout life, opening their doors to adults who wish either to resume their studies or to adapt and develop their knowledge or to satisfy their taste for learning in all areas of cultural life." [31]

The University of Warsaw is at the very beginning of the LLL/LWL integration process. We can learn a lot from the more advanced partners. Hopefully, in a short time we can also become an example of difficult and challenging, but successful implementation of new education methods, services, and innovative solutions.

\section{APPENDIX}

The courses offered by the University of Warsaw - Open University in the first trimester of 2014/2015 [32].

\section{The Culture \& Art Category:}

- What the metaphysics is? A great journey from the ancient times, via Cabala and Cartesianism, up to the $20^{\text {th }}$ century

- What the metaphysics is? A great journey from the ancient times, via Cabala and Cartesianism, up to the $20^{\text {th }}$ century - in English (B2 level)

- The Arabs. Their religion, culture, and tradition

- Beckett - the genius of French and British theatres

- Handmade jewelry

- Relationships between literature and medicine in $19^{\text {th }}$ and $20^{\text {th }}$ centuries

- Christmas decorations

- Discourses of modern culture - postmodernism in pictures

- Galicia's cultural heritage

- The history of the University of Warsaw

- The sounds of cinema. A review of sound cinematography trends

- $\quad$ Film vs. history - common dependencies and unknown contexts - part 3

- Philosophy of life and its sense

- Applied floristics

- Photography in media and modern culture - how to read photographs

- Modern photography - trends and interpretations

- Photographic inspirations

- Antic and biblical plots in the $20^{\text {th }}$ century literature

- Haaretz - the modern history, culture, and everyday life in Israel

- History of cinematography on an European culture context

- In vino veritas - French vines in life, language, and culture

- Interpretations of modern arts - a (post)critic art

- A silent cinema has a floor. A journey to the cinematography beginnings 
- The classics of photography

- The roots of design

- Cultural and existential interpretation of literature

- Modern staging of old operas

- An inhuman technology. Technological development from aesthetical and practical philosophy perspective

- The new canon of the Polish cinema

- Photography - practical workshops

- Outstanding personalities of the Polish film criticism

- Awake your creativity. Theatre and animation workshops

- From Beowulf to Shakespeare - the genesis of English language

- The Balkans - memory and identity

- Journeys with Herodot - discovering the world with ancient Greeks

- Revolutions in the arts

- $\quad$ Shock and grandeur, i.e. how to understand a modern art?

- World art and design - the modern trends

- The modern art in Poland

- The art of photographies' selection - a photoediting training

- Secrets of Paris, i.e. very cultural walks across the French capital

- A modern dance - searching for human natural move

- Tao of spiritual development

- Ethnical dances. Development of dance and vocal skills

- Introduction to Judaism

- William Shakespeare: interpretations, staging, translations

- The sixties: a society, culture, and the arts

- The artificial wall climbing

- The Warsaw architecture and beauty. Aesthetical concepts of architectural and city planning of the Polish capital

- The art of speech. Diction and voice emission.

- Water gymnastics

- Body shaping with corrective exercising

The Man \& Society Category:

- A self-massaging - you can relax your body

- "To make a life a piece of art" - Michel Foucault's concept of aestethics of existence/ self-ethics

- A sport bridge - beginner's level

- “I write myself" - philosophically, literally, and practically about biographies and autobiographies

- What do we know, and what were we persuaded? Shaping social attitudes in Polish perspective

- Develop a position of your company - how to manage a small firm effectively

- I see it in black, or how thinking influences stress and how to manage this

- What is time? A social history of time

- What is a good life and how to realize it according to classical philosophy

- Management is easy

- Manage wise - an introduction to management
- An effective management of one's own life

- Philosophy as consolation

- $\quad$ Philosophy of psychiatry

- $\quad$ Philosophy against every day reality

- Philosophy against modern problems

- Board games in school didactics

- Educational games in practice

- Modern Arabic-Muslim world

- Moral intuitions in the world

- The Islam. Short introduction

- How to make people willing to will? A motivation

- Of course you will pass the exam! Rhetoric for secondary school pupils

- Research methods in social sciences

- Creative thinking in practice

- Train the trainer - developing trainer's competencies

- Moral monsters

- Meet your child - developing upbringing competencies

- Designing educational and board games

- The etiquette of diplomacy

- $\quad$ Psychology of emotions, motivations, and personality

- Psychology of eating

- Positive psychology - learn how to be happier

- Rhetoric in every day life

- Effective self-management in stress situations

- $\quad$ Storytelling, i.e. the art of story telling

- Non-substantial addictions - psychological and social problems

- The art of discussion

- You are not listening to me, i.e. how to improve communication skills

- Creativity step by step

- Open your mind - training of innovativeness and creative thinking

- Train the trainer part 2 - advanced methods of training, with introduction to group couching

- Techniques and practical skills in project management

- The art of writing, i.e. (not only) creative writing

- Games in close relations

- A win-win approach - solving conflicts in every day life

- A perfect memory - techniques of effective remembering and knowledge fixation

- Do your best! Training in public presentations

- More than public presentations, i.e. effective rhetoric

- Developing advantages - fundaments of personal competitiveness

- $\quad$ Self-presentation and the art of public presentations

The Business, Economy \& Law Category:

- An accounting - selected aspects

- Analysis of financial reports

- The European Union for the citizens

- Practical statistics for the humanists

- Business vs. human rights

- E-business in practice - introduction to Internet business

- Introduction to econometrics in finances 
- Introduction to the companies' law

- Language etiquette and effective business communication

- Alternative investments

- How to use copyright in every day life and stay happy. Problem of intellectual ownership in social practice

- The administration code in practice

- The legislation

- The white collars' crimes

- The sale forecasting

- Taxation of the EU subventions

- Taxes in Poland - a material taxation law

- Taxes in Poland - tax obligations

- Introduction to the European private law

- Introduction to financial and management accounting

- The EU regional policy and finances

- The law and the language (part 1) - lectures on legal and administrative communication, workshops in understanding and writing of legal and administrative texts

- The law and the language (part 2)

- Evaluation and estimation of marketing activities

- Negotiations - the art of communication and conflict solving

- $\quad$ How to work effectively with the MS Excel?

- $\quad$ MS Excel - VBA language and macros (part. 1)

- $\quad$ MS Excel - VBA language and macros (part. 2)

- Introduction to data analysis in Ms Excel

- $\quad$ The MS Excel alternative: the R package in business

\section{The Science \& Technology Category:}

- Active Directory in Windows Server 2008/2012 advanced level

- $\quad$ The Linux system administration - advanced level

- Administering LAN with the Windows systems

- Chemistry and language

- The giants of physics

- Mathematics - simply, easy, and... pleasant

- Mathematics - let's fall in love!

- The art of looking: introduction to science and biology-travel photography

- Modern physics in nature and technology

- Modern physics of elementary particles and atomic nucleus

- Multimedia presentations in a pill

- The Linux system in LAN

- Nanotechnology from the beginnings - a short introduction

- The Ms Office package in practice

- A Human \& Environment category

- Resistance in health and sickness: how it develops and changes within a human's life

- $\quad$ Field forest education

- World journeys. Selected topics on regional geography

The Languages \& Nations category consists of 135 courses on different languages, CEFRL levels, or subjects (ex. business or law terminology).

\section{ACKNOWLEDGMENT}

M. D. Kisilowska thanks the Integrator project team for information concerning COME and UWOU services, and for data gathered during individual interviews with the UW authorities and staff representatives, concerning experiences, attitudes and opinions of the challenges the university is facing while implementation of lifelong learning and RPL procedure.

\section{REFERENCES}

[1] G. P. Skrzypek and B. Jałocha, "Rola i znaczenie uznawania w szkolnictwie wyższym efektów uczenia się nabytych poza edukacja formalna (RPL), the role of recognition of prior learning in the higher education area," in Uznawanie efektów uczenia się nabytych poza edukacja formalna- wyzwania projektowania systemu, G. P. Skrzypek, B. Jałocha eds., Validation of learning outcomes within non-formal and informal education: challenges for the higher education system, Zagrzeb 2013, pp. 12-13.

[2] Eurydice, "Uczenie się przez całe życie: rola systemów edukacji w państwach członkowskich Unii Europejskiej," Lifelong learning: the roles of education systems in the EU member states, Warszawa: FRSE pp. 10, 2002.

[3] E. D. Zabłocka, "Kształcenie ustawiczne - model na przyszłość? Lifelong learning - a model solution for the future?" in Ksztatcenie Przez Całe Życie: Perspektywa Małopolski, J. Gorniak, B. Worek eds., Lifelong learning: the Małopolska region perspective, Kraków: WUP Kraków 2008, pp. 15-28.

[4] Towards the European higher education area. (May 2001) Communiqué of the meeting of European Ministers in charge of Higher Education. [Online]. Available: http://europa.eu/legislation_summaries/education_training_youth/lifel ong_learning/c11088_en.htm

[5] The Educational Research Institute in Warsaw. (2014). [Online]. Available: http://www.ibe.edu.pl

[6] University of Warsaw. (2014). Centrum Otwartej i Multimedialnej Edukacji. The Centre for Open and Multimedia Education. [Online] Available:

http://portal.uw.edu.pl/web/come-community/strona-glowna

[7] Uniwersytet Otwarty Uniwersytetu Warszawskiego. The UW Open University. (2014). [Online]. Available: http://www.uo.uw.edu.pl/

[8] European Commission, Making a European Area of Lifelong Learning a Reality, 2001.

[9] Recommendation of the European Parliament and of the Council of 23 April 2008 on the Establishment of the European Qualifications Framework for Lifelong Learning, 2008.

[10] Council Recommendation of 20 December 2012 on the Validation of Non-Formal and Informal Learning, 2012.

[11] Prawo o Szkolnictwie Wyższym, the Higehr Education Law, the Law Monitor 2005 no 164 pos. 1365 with further amendments.

[12] European University Association, European Universities' Charter on Lifelong Learning, Brussels, 2009.

[13] Rozporzqdzenie Ministra Nauki i Szkolnictwa Wyższego $z$ dn. 2.11.2011 r. w sprawie Krajowych Ram Kwalifikacji dla Szkolnictwa Wyższego, (the Ministry of Science and Higher Education Regulation on 11/02/2011 on the National Qualifications Framework for Higehr Education), the Law Monitor 2011 no 253 pos. 1520.

[14] E. Chmielecka, Autonomia Programowa Uczelni: Ramy Kwalifikacji Dla Szkolnictwa Wyższego, a university's autonomy of teaching. qualifications framework for higher education, Warsaw: Ministerstwo Ministry of Science and Higher Education, 2010.

[15] P. Werquin, Recognition of Non-Formal and Informal Learning. Country Practices, OECD, 2010.

[16] G. P. Skrzypek et al., Recognition of Prior Learning in Higher Education - Challenges of Designing the System, Zagreb: Institute for the Development of Education, 2013.

[17] Sprawozdanie Rektora Uniwersytetu Warszawskiego z działalności uczelni w 2013 r. The UW Rector report on the university's activity in 2013. [Online]. Available: http://www.uw.edu.pl/wp-content/uploads/2014/06/SprawozdanieUW 2013.pdf

[18] Commission of the European Communities, Communication from the Commission: e-Learning - Designing Tomorrow's Education, COM, 2000.

[19] Uniwersytet Dzieci. (2014). [Online]. Available: http://www.uniwersytetdzieci.pl/ 
[20] Council of Europe, Europejski System Opisu Kształcenia Językowego: Uczenie Sie, Nauczanie, Ocenianie, the Common European Framework of Reference for Languages: Learning, teaching, evaluating, Warsaw: CODN, 2001.

[21] University of Warsaw. (2014). The Modern University. [Online]. Available: http://www.nuw.uw.edu.pl/eng/

[22] M. Boni. (2009). Polska 2030 - Wyzwania Rozwojowe. Poland 2030 challenges for development. Warsaw: The Prime Minister Chancellery. [Online]. Available: http://www.mir.gov.pl/aktualnosci/ministerstwo/Documents/polska_2 030_raport_0609.pdf

[23] Raport Samopotwierdzenia Krajowych Ram Kwalifikacji Dla Szkolnictwa Wyższego, Report on the National Qualifications Framework for Higher Education, Warsaw: IBE, 2013, pp. 66-67.

[24] K. L. Cichocka, "Rozwój kształcenia ustawicznego w polskich uczelniach wyższych na przykładzie Uniwersytetu Otwartego Uniwersytetu Warszawskiego, (Studia biura analiz sejmowych, bureau of research - chancellery of the parliament studies)," Development of life long learning in Polish higher education institutions. Case study of the UW Open University, vol. 3, no. 35, pp. 213-248, 2013.

[25] K. L. Cichocka, "Praktyczna realizacja idei kształcenia ustawicznego na przykładzie uniwersytetu otwartego uniwersytetu warszawskiego, (Implementation of the life long learning idea. Case study of the UW Open University)," Ph.D. dissertation, Dept. Paedag. Univ. of Warsaw, Warsaw, Poland, 2013.

[26] Polish Children's Fund. (2014). [Online]. Available: http://fundusz.org/english

[27] UW Faculty of Chemistry, Misja Wydzialu Chemii Uniwersytetu Warszawskiego, (The mission of the UW Faculty of Chemistry), Warsaw, 2012.
[28] UW Faculty of Philosophy and Sociology, Uchwata nr 40/2013 Rady Wydziału Filozofii i Socjologii UW z dnia 25 czerwca 2013 w sprawie misji i strategii Wydziatu Filozofii i Socjologii UW, (the Faculty of Philosophy and Sociology Council Resolution No 40/2013 on 06/25/2013 on the Faculty's Mission and Strategy), Warsaw, 2013.

[29] UW Faculty of History, "Misja i strategia wydziału historycznego uniwersytetu warszawskiego, (The mission and strategy of the UW faculty of history)," Warsaw, 2012.

[30] Commission of the European Communities, Adult Learning: It is Never too Late to Learn, COM, 2006, pp. 1.

[31] J. Delors, "Learning: the treasure within," Report to UNESCO of the International Commission on Education for the Twenty-first Century, Paris: UNESCO Publishing 1996, pp. 25.

[32] University of Warsaw. (2014). The Open University - list of courses available. [Online]. Available: http://www.uo.uw.edu.pl/kursy

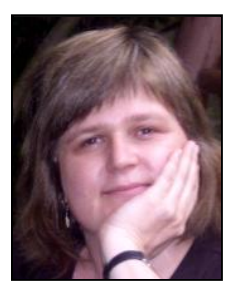

Malgorzata D. Kisilowska is an assistant professor in humanities, bibliology and information science, at the University of Warsaw, Faculty of History, Department of Information and Book Studies, Warsaw, Poland, 2010.

She has been working as a researcher and lecturer in the University of Warsaw since 1994 at the Department of Information and Book Studies. She has been a deputy director for Students Affairs during 2001-2008 and the chair of the rector's commission on curricula in humanities. Prof. Kisilowska is a member of the Polish Society of Bibliology. 